\title{
Innovations in the Management of Marketing Activities of the Higher Education System
}

\author{
M.O. Surayeva ${ }^{1}$, I.A. Grigoryants ${ }^{1}$, N.V. Kochetkova ${ }^{1, *}$, and A.N. Evdokimov ${ }^{1}$ \\ *Corresponding author: nvkochetkova@bk.ru. \\ ${ }^{1}$ Samara State University of Economics, Samara, Russia
}

\begin{abstract}
Modern educational organization is actually a full member of market relations. Universities now have the right to make money and manage it. On the education market there are many factors that affect the stability of the educational organization. The authors made an attempt to analyze the factors and risks in the education market. Analyzing the set of factors operating in the education market, the authors identify the most dangerous of them, which currently affect the sustainable functioning of universities. It is proposed to solve the problem of sustainable functioning of the University with the use of marketing management as one of the components of management studying market processes.
\end{abstract}

Keywords: marketing, sustainability, University, education system, management.

\section{Introduction}

The relationship between the participants of higher education in the Russian Federation has undergone significant changes in recent decades due to the change of socio-economic foundations of society. In relation to higher education, this has caused a change in the system and mechanisms of regulation by the state, restructuring of sources of funding due to public underfunding, increased competition, reform in this area, the transition to new standards of education.

The education sector is under considerable pressure from environmental factors, which negatively affects the sustainability of the functioning of universities:

- unfavorable demographic situation in the Russian Federation, which takes place today, the consequence of which is the disproportion between the increasing supply of universities and the decreasing number of applicants;

- the deterioration of economic development, which has led to the inability of a large number of people to pay for increasingly expensive educational services.

In this regard, there is a need to improve the management system of universities, which is recognized by both the scientific community and society.

\section{Methods}

The problem of unstable functioning of universities can be solved by modeling the marketing management system. It is the marketing approach that will allow universities to adapt to the dynamics of the external environment. The basis of marketing management is the satisfaction and formation of the population's demand for educational services. Active marketing policy is necessary for the development of educational programs that will prepare qualified personnel that meet the interests of the labor market.

Many aspects of marketing management of sustainability of higher education functioning are not sufficiently developed and need to be clarified taking into account the changes. Stability and risk of the social system are interrelated concepts. At the heart of the categorical structure of risk theory is the concept of "the danger of losing something." Under the risk can be understood the threats that are fraught with the external environment identified in the SWOT analysis. The threat is what the university risks when it comes to negative events. This is an objective regularity that determines the processes of quantitative and qualitative changes in the systems perceived as a threat to the vital interests of people.

From the point of view of the theory of systemic risks are considered as a property inherent in any type of expedient activities, manifested as the uncertainty of the implementation of the objective functions, the nature, content, direction and conditions of achievement of which are not fully clear to the decision-maker. Considering the risks of systems of any level of complexity allows us to classify them by forms of manifestation and investigate them as relatively stable and repetitive.

The complexity of the system of public relations, the growth of overall productivity, the creation of a system of mass consumption leads to the fact that an increasing number of individuals who are excluded from the production process and become passive consumers. In these conditions, there are growing risks associated with the fact that resources aimed at education, professional training of large groups of people will never pay off.

Therefore, risk assessment through a system of quantitative indicators will minimize the costs of the company to divert resources to various reserve funds. Destructive risks, as a rule, cannot be accurately quantified, information about them is mostly probabilistic and is not available to most business entities. This is due to the fact that the qualitative parameters of possible losses are so great that the company is not able to create reserve funds to eliminate the damage 
from the occurrence of destructive risks. Production risks are risks associated with the possibility of shortfall in profits or losses as a result of inefficient cost management, personnel and as a result of errors in the choice of strategies to increase productivity, product differentiation.

\section{Results}

In the scientific literature there are various approaches to the definition of risk parameters [1, 2]. Some authors consider risk as one of the types of danger associated with political, social and economic activities of people [3]. Other do bias in the direction of the man-made nature of the risk [4]. The third group of authors examines risks as a form of uncertainty of the result, which is associated with a special type of economic activity [5]. Within the framework of this direction, the regularities of the risks manifestation are investigated, which in the conditions of the system functioning have a set of maxima, each of which violates different equilibrium States. Particular attention is paid to such characteristics of risks as entropy, which is a measure of uncertainty of a certain state of the system, which violates its equilibrium.

The main indicator of risk is the probability of occurrence in time of events leading to changes in the equilibrium stability of socio-economic systems. Their source is the conditions and factors that cause uncertainty in the state of the system. In management theory, there are many types of uncertainty. Most of them are related not to the effect of direct impact on the targets, but to the time parameter of this influence. Uncertainty is considered relative to the time when a negative event occurs [6].

Along with the above types of risk should be identified the concept of marketing risk. Marketing risk is the danger of mismatch of needs and opportunities to meet them. Achieving a result is always multivariate, therefore, there is a multiple opportunity to minimize the needs and costs to ensure the stability of the system. Marketing risks are largely determined by SWOT analysis.

Management of marketing risks should be carried out minimizing them by matching the needs and opportunities in the socio-economic system.

It is possible to allocate following characteristics of risks of the marketing:

- mismatch of goals and results of expedient activities in social, political and economic spheres;

- deviation of the actual result from the possible one, which is defined as the base (threshold) value.

Marketing risks can be classified on such methodological grounds as the nature and form of manifestation. The nature refers to the essential features of economic risks, the manifestation of which causes damage, leads to losses and reduces the level of rationality and efficiency of the use of limited resources and factors of production.

The risk of any system, including marketing, is characterized by resource (material) and spiritual contradictions in the system, determined by the transition of the system from one state (when the system has a disaster - partial performance of the system's functions) to another (in which the system does not have a disaster - the full performance of the system's functions).

Universities education institutions are part of the socio-economic environment and all changes in it are reflected in universities. Universities are full participants of market relations. Increased competition in the field of educational services requires a marketing approach to the management of the University.

Modern educational organization interacts with a huge number of different objects, which is reflected in figure 1.

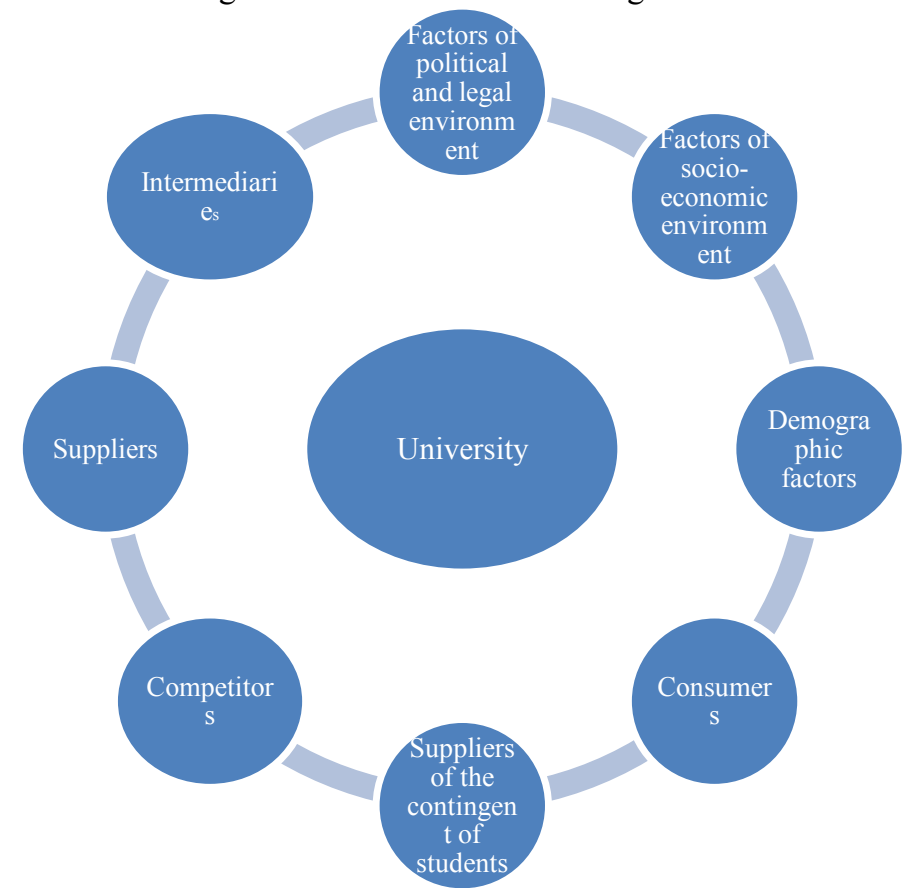

Fig. 1. The structure factors of the marketing environment of the University (Source: Authors.) 
The author's analysis of the factors of the external environment of the University showed that the activities of educational institutions have a pronounced social character. The social orientation of educational institutions creates conditions for solving a wide range of socially significant problems. Therefore, the concept of socially responsible marketing, according to the author, is fundamental in the activities of the University.

Elements of this concept contribute to the establishment of social responsibility of educational institutions and are key factors in the formation of the image of the University.

Since the University is a participant of market relations, its ability to adapt to changes in the external environment is of great importance.

A feature of a large University is a significant inertia, which can be compensated only through marketing research activities, which will allow to timely identify threats from the external environment and develop measures to avoid or reduce the negative consequences of their occurrence.

\section{Conclusion}

The University is an open system that has the ability to transform the external environment, that is, the system is able not only to respond to changes in the dynamics of the external environment, but also to provoke them. In the process of such interaction, the structure and functioning of the University are changing in order to ensure its sustainability.

Adaptation to changes in the environment and the structuring of its elements are made possible through the use of a marketing approach to the management of the University. The right strategy and tactics of marketing management will lead to the sustainability of the educational institution.

\section{References}

1. E.P. Pecherskaya, L.V. Averina, L.G Karanatova, S.A. Kozhevnikova, Innovation educational institutions as a point of growth in digital economy. In V.V. Mantulenko (Ed.), Proceedings of the International Scientific Conference "Global Challenges and Prospects of the Modern Economic Development", GCPMED-2019. European Proceedings of Social and Behavioural Sciences, 57 (pp. 365-372). London: Future Academy (2019). DOI: 10.15405/epsbs.2019.03.36.

2. I.K. Belyaevsky, G.D. Kulagina, L.A. Dancheno, A.V. Korotkov, A.A. Romanov, V.V. Usov, Statistics of market of goods and services (Finances and Statistics, Moscow, 2002). [in Rus.].

3. E.A. Kandrashina, A.M. Izmailov, V.V. Mantulenko, N.S. Mirzayev, Theoretical aspects of gaps formation in the system of Russian higher education, In V.V. Mantulenko (Ed.) Proceedings of the International Scientific Conference "Global Challenges and Prospects of the Modern Economic Development", GCPMED-2019. European Proceedings of Social and Behavioural Sciences, 57 (pp. 1135-1142). London: Future Academy (2019). DOI: 10.15405/epsbs.2019.03.114.

4. N.N. Pavlova, Features of the service and its marketing. Librarium (2009). URL: http://www.elitarium.ru/2009/01/23/osobennosti_marketinga_uslugi.html. Accessed 12.09.2019. [in Rus.].

5. S.I. Ashmarina, E.A. Kandrashina, I.A. Plaksina, Interest alignment model in the higher education system. In V. Mantulenko (Ed.), Proceedings of the 17th International Scientific Conference "Problems of Enterprise Development: Theory and Practice” (November 26-27, 2018, Samara. Russia). SHS Web of Conferences, 62, 12001 Les Ulis: EDP Sciences (2019). DOI: 10.1051/shsconf/20196212001.

6. V.K. Chertykovcev, A.N. Bogusonov, To the question of stability of economic systems. Bulletin of Saratov State Socio-Economic University, 2(13), 78-79 (2006). [in Rus.]. 